\title{
BMJ
}

\section{Neurological outcomes at 18 months of age after moderate hypothermia for perinatal hypoxic ischaemic encephalopathy: synthesis and meta-analysis of trial data}

\author{
A David Edwards, professor of neonatal medicine, ${ }^{1,2}$ Peter Brocklehurst, director , ${ }^{3}$ Alistair J Gunn, professor of \\ physiology, ${ }^{4}$ Henry Halliday, professor of perinatal medicine, ${ }^{5,6}$ Edmund Juszczak, head of trials, ${ }^{3}$ Malcolm \\ Levene, professor of paediatrics and child health,, ${ }^{7,8}$ Brenda Strohm, trial coordinator, ${ }^{3}$ Marianne Thoresen, \\ professor of neonatal neuroscience, ${ }^{9}$ Andrew Whitelaw, professor of neonatal medicine, ${ }^{9}$ Denis Azzopardi, \\ clinical reader in neonatal medicine ${ }^{1,2}$
}

Institute of Clinical Sciences, Faculty of Medicine, Imperial College London, London SW7 2AZ

${ }^{2}$ Medical Research Council Clinical Sciences Centre, Hammersmith

Hospital, Imperial College London, London W12 ONN

${ }^{3}$ National Perinatal Epidemiology Unit, Department of Public Health, University of Oxford, Oxford OX3 7LF

${ }^{4}$ Department of Physiology, School of Medical Sciences, University of Auckland, Auckland 1142, New Zealand

${ }^{5}$ Royal Jubilee Maternity Service, Royal Maternity Hospital, Belfast BT12 6BA

${ }^{6}$ Department of Child Health, Queen's University of Belfast, Belfast BT12 6BL

${ }^{7}$ University of Leeds, Leeds LS1 3BR

${ }^{8}$ Leeds General Infirmary, Leeds LS1 3EX

${ }^{9}$ Department of Clinical Science at South Bristol, Faculty of Medicine and Dentistry, University of Bristol, St Michael's Hospital, Bristol BS2 8EG

Correspondence to: D Azzopardi d.azzopardi@imperial.ac.uk

Cite this as: BMJ 2010;340:c363 doi:10.1136/bmj.c363

\section{ABSTRACT}

Objective To determine whether moderate hypothermia after hypoxic-ischaemic encephalopathy in neonates improves survival and neurological outcome at 18 months of age.

Design A meta-analysis was performed using a fixed effect model. Risk ratios, risk difference, and number needed to treat, plus $95 \%$ confidence intervals, were measured.

Data sources Studies were identified from the Cochrane central register of controlled trials, the Oxford database of perinatal trials, PubMed, previous reviews, and abstracts. Review methods Reports that compared whole body cooling or selective head cooling with normal care in neonates with hypoxic-ischaemic encephalopathy and that included data on death or disability and on specific neurological outcomes of interest to patients and clinicians were selected.

Results We found three trials, encompassing 767 infants, that included information on death and major neurodevelopmental disability after at least 18 months' follow-up. We also identified seven other trials with mortality information but no appropriate neurodevelopmental data. Therapeutic hypothermia significantly reduced the combined rate of death and severe disability in the three trials with 18 month outcomes (risk ratio $0.81,95 \%$ confidence interval 0.71 to $0.93, \mathrm{P}=0.002$; risk difference $-0.11,95 \% \mathrm{Cl}-0.18$ to $-0.04)$, with a number needed to treat of nine $(95 \% \mathrm{Cl} 5$ to 25). Hypothermia increased survival with normal neurological function (risk ratio $1.53,95 \% \mathrm{Cl} 1.22$ to 1.93 , P<0.001; risk difference $0.12,95 \% \mathrm{Cl} 0.06$ to 0.18 ), with a number needed to treat of eight $(95 \% \mathrm{Cl} 5$ to 17$)$, and in survivors reduced the rates of severe disability $(P=0.006)$, cerebral palsy $(P=0.004)$, and mental and the psychomotor developmental index of less than 70 $(P=0.01$ and $P=0.02$, respectively). No significant interaction between severity of encephalopathy and treatment effect was detected. Mortality was significantly reduced when we assessed all 10 trials (1320 infants; relative risk $0.78,95 \% \mathrm{Cl} 0.66$ to $0.93, \mathrm{P}=0.005$; risk difference $-0.07,95 \% \mathrm{Cl}-0.12$ to -0.02$)$, with a number needed to treat of 14 ( $95 \% \mathrm{Cl} 8$ to 47$)$.

Conclusions In infants with hypoxic-ischaemic encephalopathy, moderate hypothermia is associated with a consistent reduction in death and neurological impairment at 18 months.

Perinatal hypoxic-ischaemic encephalopathy is a major cause of death and disability worldwide for which no specific therapy has been available. ${ }^{1}$ Studies have shown that neural damage after hypoxia-ischaemia is delayed for several hours and that treatment with prolonged moderate hypothermia reduces cerebral injury and improves neurological outcome. ${ }^{2}$ Several clinical trials of the application of therapeutic hypothermia during perinatal hypoxic-ischaemic encephalopathy have been reported. ${ }^{3-6}$ Unfortunately, the results of these trials are not conclusive- the few studies that report neurological outcomes at 18 months of age or more use a composite primary outcome of death or disability, which makes precise interpretation difficult. In addition, although the studies produce point estimates that show a treatment benefit, the estimates only reach conventional statistical significance in one report. ${ }^{5}$

A systematic review published by the Cochrane Library in 2007 concluded that 72 hours of moderate hypothermia started within 6 hours of birth reduces the rate of death and disability at 18 months of age. ${ }^{7}$ Experts and clinicians were hesitant about this finding, however, because the data were incomplete and inadequate to permit any comment on neurodevelopmental outcomes in survivors or to address important issues such as whether the efficacy of hypothermia is moderated by the severity of encephalopathy.

Consequently, controversy exists over the value of hypothermia after hypoxic-ischaemic encephalopathy, and consensus has not been reached. A workshop convened by the National Institute of Child Health and Human Development in 2006 concluded that 
therapeutic hypothermia was an evolving therapy and the evidence was not sufficient to support making it the standard of care. ${ }^{8}$ This view was endorsed by the American Academy of Pediatrics committee on the fetus and newborn. ${ }^{9}$

New studies have been published since the Cochrane review was conducted, including the Total Body Hypothermia (TOBY) trial, the largest randomised controlled trial of hypothermia for perinatal encephalopathy. ${ }^{6}$ The TOBY trial reports the neurological outcome of 325 infants at 18 months of age, but does not provide conclusive evidence on the efficacy of therapeutic hypothermia because it failed to detect a significant benefit regarding the primary outcome of death or disability.

We report a meta-analysis of new studies and recently available additional data from previously reported studies that defines the confidence with which therapeutic hypothermia might be used to reduce death and disability after hypoxia-ischaemia, determines its effect on neurological outcomes in infants who survive perinatal hypoxic-ischaemic encephalopathy, and considers whether the therapeutic effect is restricted to infants with moderate encephalopathy.

\section{METHODS}

Relevant studies were identified from the Cochrane central register of controlled trials, the Oxford database of perinatal trials, PubMed (using the Mesh terms ("Infant, Newborn" AND "Hypoxia-Ischemia, Brain") and "Hypothermia, Induced"), previous reviews, and abstracts up to July 2009, and additional unpublished data were sought and obtained from investigators of published studies and unpublished studies. The identification of studies was carried out by members of our study group, and the selection of relevant studies was by consensus.

We assessed the methodological quality of the studies according to whether they used randomisation and blinding to the intervention and on the basis of completeness and blinding of follow-up, as recommended by the neonatal review group of the Cochrane Collaboration. ${ }^{10}$ We selected reports that included data on death or disability and on specific neurological outcomes of interest to patients and clinicians, such as cerebral palsy or survival with normal neurological function. We used this dataset to examine the effect of prolonged moderate hypothermia on the following outcomes: the combined rate of death and disability; the rate of survival without neurological abnormality; the rate of severe disability; the rate of cerebral palsy; scores on the mental developmental and psychomotor indices of the Bayley scales of infant development ${ }^{11}$; and the quality of vision and hearing.

We used all studies that reported mortality to analyse the effect of hypothermia on mortality. This decision was based on our reasoning that the majority of deaths from perinatal hypoxic-ischaemic encephalopathy would occur in the neonatal period, thus mortality would be appropriately captured even when follow-up did not continue until 18 months of age. To analyse neurological outcomes, we selected completed randomised controlled trials that assessed neurological outcomes to at least 18 months of age. Composite neurological outcomes are reported for all infants randomly allocated to a study arm, with the number of infants not followed up included in the denominator when calculating the rates of the composite outcomes. Individual neurological outcomes are reported for survivors with available follow-up data.

Meta-analysis was performed with the Review Manager software (RevMan Version 5.0; Nordic Cochrane Centre, Copenhagen, Denmark) using the Mantel-Haenszel method and a fixed effect model. We calculated risk ratios and risk difference for dichotomous variables, with 95\% confidence intervals, and the number needed to treat, which is the reciprocal of the risk difference, with $95 \%$ confidence intervals.

To determine whether the benefit of hypothermia on death or disability was affected by the severity of encephalopathy, we examined subgroups for which the severity of encephalopathy was graded as moderate or severe on the basis of clinical examination and/or amplitude integrated electroencephalography in trials that reported neurological outcome at 18 months of age or more. Grade of encephalopathy assessed by amplitude integrated electroencephalography considered to be equivalent to that of the clinical assessment. The consistency of the treatment effect across subgroups was explored by calculating the ratio of relative risks with $95 \%$ confidence interval. ${ }^{12}$

All statistical tests were two sided and not adjusted for multiple comparisons. A $\mathrm{P}$ value $<0.05$ was considered statistically significant. We examined heterogeneity among studies by using the $\chi^{2}$ and the $\mathrm{I}^{2}$ tests.

\section{RESULTS}

We compiled a dataset of 1320 infants from 10 randomised controlled trials for whom at least mortality data were available. ${ }^{3-613-18}$ A simplified summary of the trial characteristics is provided in table 1 .

Neurological outcomes up to at least 18 months of age were available for a subset of three trials comprising 767 infants: a trial by the CoolCap study group, ${ }^{4}$ a National Institute of Child Health and Human Development (NICHD) study, ${ }^{5}$ and the TOBY trial. ${ }^{6}$ These three trials had similar entry criteria: evidence of birth asphyxia; and moderate or severe encephalopathy. The entry criteria for the CoolCap and TOBY trials also included abnormal amplitude integrated electroencephalogram. Infants were at least 36 weeks' gestation at recruitment, and random allocation was completed by 6 hours after birth. In the CoolCap study, cooling was achieved by circulating cooling fluid in a cap, with a target rectal temperature of $34.5^{\circ}$ $\mathrm{C}$, and was maintained for 72 hours. In the TOBY and NICHD trials, whole body cooling to $33.5^{\circ} \mathrm{C}$ was induced by cooling blankets placed under the infants.

Two other pragmatic trials with a planned follow-up at 18 months were in progress at the time of our meta-analysis and had not yet reported their results in full: the Infant Cooling Evaluation (ICE) trial, which 
Table 1| Summary of randomised trials of moderate hypothermia for perinatal hypoxic-ischaemic encephalopathy

\begin{tabular}{|c|c|c|c|c|c|c|}
\hline Study & $\begin{array}{l}\text { Ratio cooled: } \\
\text { controls }\end{array}$ & $\begin{array}{l}\text { Cooling } \\
\text { method }\end{array}$ & $\begin{array}{l}\text { Core temperature } \\
\text { achieved }\left({ }^{\circ} \mathrm{C}\right)\end{array}$ & $\begin{array}{c}\text { Duration of } \\
\text { cooling (hours) }\end{array}$ & Primary outcome & Follow-up period \\
\hline Eicher et al, $2005^{3}$ & $32: 33$ & Systemic & 33 & 48 & Rates of death and severe disability & 12 months \\
\hline $\begin{array}{l}\text { CoolCap trial } \\
\text { (Gluckman et al, 2005) }^{4}\end{array}$ & $116: 118$ & Selective & $34-35$ & 72 & Rates of death and severe disability & 18 months \\
\hline $\begin{array}{l}\text { NICHD trial } \\
(\text { Shankaran et al, 2005) })^{5}\end{array}$ & $102: 106$ & Systemic & 33.5 & 72 & $\begin{array}{l}\text { Rates of death, moderate disability, and severe } \\
\text { disability }\end{array}$ & 18 months \\
\hline $\begin{array}{l}\text { TOBY trial } \\
\text { (Azzopardi et al, 2009) }^{6}\end{array}$ & $163: 162$ & Systemic & $33-34$ & 72 & Rates of death and severe disability & 18 months \\
\hline $\begin{array}{l}\text { ICE trial } \\
\text { (Jacobs et al, 2008) }^{13}\end{array}$ & $110: 111$ & Systemic & $33-34$ & 72 & Rates of death and severe disabilities & 24 months \\
\hline $\begin{array}{l}\text { neo.nEURO.network trial } \\
\text { (Simbruner et al, 2008) }^{14}\end{array}$ & $64: 65$ & Systemic & $33-34$ & 72 & Rates of death and severe disability & 18 months \\
\hline Robertson et al, $2008^{15}$ & $21: 15$ & Systemic & $33-34$ & 72 & Mortality, neurological assessment, and seizures & 17 days \\
\hline Lin et al, $2006^{16}$ & $32: 30$ & Selective & $34-35$ & 72 & $\begin{array}{c}\text { Findings on computed tomogram and } \\
\text { neurological assessment }\end{array}$ & 7-10 days \\
\hline Akisu et al, $2003^{17}$ & $11: 10$ & Selective & 36.5 & 72 & $\begin{array}{l}\text { Levels of platelet activating factor in } \\
\text { cerebrospinal fluid }\end{array}$ & 4-10 days \\
\hline Shankaran et al, $2002^{18}$ & $9: 10$ & Systemic & 34.5 & 72 & Clinical course until hospital discharge & $\begin{array}{l}\text { Until hospital } \\
\text { discharge }\end{array}$ \\
\hline
\end{tabular}

Abbreviations: ICE, Infant Cooling Evaluation; NICHD, National Institute of Child Health and Human Development; TOBY, Total Body Hypothermia.

enrolled 221 infants and was expected to complete follow-up by late $2009,{ }^{13}$ and the neo.nEURO.network trial of 129 infants, which has not yet been fully analysed or reported. ${ }^{14}$ One randomised pilot study of 36 infants carried out in Uganda reported outcomes to 17 days of age. ${ }^{15}$ The trials carried out in China that were included in previous systematic reviews have still not reported 18 month outcomes. ${ }^{1619}$ Further explanatory data from previously analysed trials have been published or were made available specifically for the present review. ${ }^{62021}$

We excluded from the analysis a report of 31 randomised infants who were part of a series of studies that also included infants who were assigned treatment on a non-random basis and were treated with varying degrees of hypothermia. ${ }^{223}$ One trial of 65 infants that reported outcome only to 12 months of age was excluded from the analysis of neurological outcomes but was included in the analysis of mortality data. ${ }^{3}$

\begin{tabular}{|c|c|c|c|c|c|c|c|}
\hline \multirow[b]{2}{*}{ Study or subgroup } & \multicolumn{2}{|c|}{ Hypothermia } & \multicolumn{2}{|c|}{ Normothermia } & \multirow[b]{2}{*}{$\begin{array}{c}\text { Risk ratio } \\
(95 \% \mathrm{Cl})\end{array}$} & \multirow[b]{2}{*}{$\begin{array}{c}\text { Weight } \\
\text { (\%) }\end{array}$} & \multirow[b]{2}{*}{$\begin{array}{c}\text { Risk ratio } \\
(95 \% \mathrm{Cl})\end{array}$} \\
\hline & Events & Total & Events & Total & & & \\
\hline TOBY & 74 & 163 & 86 & 162 & $\rightarrow$ & 39.0 & 0.86 (0.68 to 1.07$)$ \\
\hline $\mathrm{NICHD}$ & 45 & 102 & 64 & 106 & $\rightarrow$ & 28.3 & 0.73 (0.56 to 0.95$)$ \\
\hline CoolCap & 59 & 116 & 73 & 118 & $\rightarrow-$ & 32.7 & $0.82(0.65$ to 1.03$)$ \\
\hline Total $(95 \% \mathrm{Cl})$ & & 381 & & 386 & $\bullet$ & 100.00 & 0.81 ( 0.71 to 0.93$)$ \\
\hline \multirow[t]{2}{*}{ Total events } & 178 & & 223 & 0.2 & 0.51 & 5 & \\
\hline & & & & $\begin{array}{l}\text { Favou } \\
\text { hypot }\end{array}$ & ermia norm & $\begin{array}{l}\text { ours } \\
\text { rmia }\end{array}$ & \\
\hline
\end{tabular}

Fig 1 | Forest plot of the effect of therapeutic hypothermia compared with standard care (normothermia) on death or disability ("events"). All infants randomly assigned to either study arm were included in the analysis. A Mantel-Haenszel fixed effects model was used to calculate risk ratios and $95 \%$ confidence intervals. Test for heterogeneity: $X^{2}=0.82$, degrees of freedom=2 ( $P=0.66) ; I^{2}=0 \%$. Test for overall effect: $Z=3.03(P=0.002)$. Studies shown are the Total Body Hypothermia (TOBY) trial, ${ }^{6}$ the National Institute of Child Health and Human Development (NICHD) trial, ${ }^{5}$ and the CoolCap trial ${ }^{4}$

\section{Methodological quality of the dataset}

In the three trials that report neurological outcomes to 18 months, none blinded caregivers to the treatment assignment. Follow-up to at least 18 months of age by assessors masked to allocation was available for 218 $(93 \%)$ of the 234 infants in the CoolCap trial, 205 $(99 \%)$ of the 208 infants in the NICHD trial, and 323 (99\%) of the 325 infants in the TOBY trial.

The methodological quality of six of the 10 trials included in the assessment of mortality was reported in a 2007 Cochrane review $^{7}$; allocation concealment was considered inadequate in the study of Lin et al. ${ }^{16}$ The four remaining studies used appropriate methodology. ${ }^{613-15}$

Primary outcome: death or disability at 18 months

The primary outcome for all three trials was the combined rate of mortality and disability. Disability was defined in the CoolCap and TOBY trials as the presence of at least one of the following impairments: mental development index score of less than 70 (that is, 2 standard deviations from a standardised mean of 100) on the Bayley scales of infant development; gross motor function classification system level 3-5 (where the scale is from 1 to 5 , with 1 being the mildest impairment); or bilateral cortical visual impairment with no useful vision. The NICHD trial defined disability as a mental developmental index score of 70-84 plus one or more of the following impairments: gross motor function classification system level 2; hearing impairment with no amplification; or a persistent seizure disorder.

Each of these three trials showed a reduction in the risk of mortality and disability in infants who underwent therapeutic hypothermia, but the finding was statistically significant only in the NICHD trial (fig 1). Meta-analysis of the three trials showed that therapeutic hypothermia significantly reduced the risk of death 


\begin{tabular}{|c|c|c|c|c|c|c|c|}
\hline \multirow[b]{2}{*}{ Study or subgroup } & \multicolumn{2}{|c|}{ Hypothermia } & \multicolumn{2}{|c|}{ Normothermia } & \multirow[b]{2}{*}{$\begin{array}{c}\text { Risk ratio } \\
(95 \% \mathrm{Cl})\end{array}$} & \multirow[b]{2}{*}{$\begin{array}{l}\text { Weight } \\
\text { (\%) }\end{array}$} & \multirow[b]{2}{*}{$\begin{array}{c}\text { Risk ratio } \\
(95 \% \mathrm{Cl})\end{array}$} \\
\hline & Events & Total & Events & Total & & & \\
\hline CoolCap & 29 & 116 & 20 & 118 & 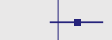 & 22.9 & 1.48 (0.89 to 2.45 ) \\
\hline $\mathrm{NICHD}$ & 32 & 102 & 22 & 106 & $\rightarrow$ & 24.9 & 1.51 (0.94 to 2.42$)$ \\
\hline TOBY & 71 & 163 & 45 & 162 & $\rightarrow$ & 52.2 & 1.57 (1.16 to 2.12 ) \\
\hline Total $(95 \% \mathrm{Cl})$ & & 381 & & 386 & 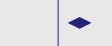 & 100.00 & 1.53 (1.22 to 1.93$)$ \\
\hline \multirow[t]{2}{*}{ Total events } & 132 & & 87 & & $\begin{array}{lll}0.5 & 1 & 2\end{array}$ & $5 \quad 10$ & \\
\hline & & & & & rmia hy & $\begin{array}{l}\text { Favours } \\
\text { thermia }\end{array}$ & \\
\hline
\end{tabular}

Fig 2 | Forest plot of the effect of therapeutic hypothermia compared with standard care (normothermia) on survival with normal neurological function ("events"). All infants randomly assigned to either study arm were included in the analysis. A Mantel-Haenszel fixed effects model was used to calculate risk ratios and $95 \%$ confidence intervals. Test for heterogeneity: $X^{2}=0.05$, degrees of freedom $=2(P=0.66) ; I^{2}=0 \%$. Test for overall effect: $Z=3.66(P=0.0003)$. Studies shown are the Total Body Hypothermia (TOBY) trial, ${ }^{6}$ the National Institute of Child Health and Human Development (NICHD) trial, ${ }^{5}$ and the CoolCap trial ${ }^{4}$

or disability at 18 months (relative risk $0.81,95 \% \mathrm{CI}$ 0.71 to $0.93, \mathrm{P}=0.002$; risk difference $-0.11,95 \% \mathrm{CI}$ -0.18 to -0.04$)$, with a number needed to treat of nine $(95 \%$ CI 5 to 25$)$.

\section{Secondary outcomes}

Meta-analysis of the CoolCap, NICHD, and TOBY trials showed that treatment with hypothermia was consistently associated with an increased rate of normal survival, defined as survival without cerebral palsy and with a mental developmental index score of more than 84 , a psychomotor development index score of more than 84 , and normal vision and hearing (fig 2; relative risk $1.53,95 \%$ CI 1.22 to $1.93, \mathrm{P}<0.001$; risk difference $0.12,95 \%$ CI 0.06 to 0.18 ), with a number needed to treat of eight (95\% CI 5 to 17). Among infants who survived to 18 months of age, those treated with hypothermia had significantly lower rates of severe disability $(\mathrm{P}=0.006)$, cerebral palsy $(\mathrm{P}=0.004)$, severe neuromotor delay (psychomotor developmental index score $<70$; $\mathrm{P}=0.02$ ), severe neurodevelopmental delay (mental developmental index score $<70 ; \mathrm{P}=0.01)$, and blindness $(\mathrm{P}=0.03$; table 2). The rate of deafness was $4.7 \%$ (12/ $255)$ in infants treated with hypothermia and $6 \%$ (14/ 227 ) in controls $(\mathrm{P}=0.47)$. $\mathrm{I}^{2}$ was $0 \%$ for all analyses of neurological outcomes, indicating no heterogeneity among studies (fig 3).

Analysis of data from all 10 trials that reported mortality rates showed that infants treated with prolonged moderate hypothermia were less likely to die than those who received normal care (fig 4). A total of 169 $(26 \%)$ of the 660 infants treated with therapeutic hypothermia died, compared with 217 (33\%) of the 660 infants who received standard care (relative risk $0.78,95 \%$ CI 0.66 to $0.93, \mathrm{P}=0.005$; risk difference $-0.07,95 \% \mathrm{CI}-0.12$ to -0.02$)$, with a number needed to treat of $14(95 \%$ CI 8 to 47$)$. Only the Uganda study showed an excess mortality in infants who underwent therapeutic hypothermia (7/21 cooled infants died $v 1 /$ 15 non-cooled infants). ${ }^{15}$

\section{Effect of severity of encephalopathy}

The severity of encephalopathy at random allocation was assessed by amplitude of integrated electroencephalogram and by clinical assessment in the CoolCap study, by clinical assessment only in the NICHD study, and by amplitude of integrated electroencephalogram only in the TOBY trial. For the CoolCap study, we used only the clinical assessment of encephalopathy for our meta-analysis because this outcome was comparable with that used in the NICHD study. ${ }^{20}$ Meta-analysis showed that the relative risk for the combined outcome of death or severe disability was lower in infants with moderate encephalopathy $(0.73,95 \%$ CI 0.58 to $0.92 ; \mathrm{P}=0.008)$ than in those with severe encephalopathy $(0.87,95 \%$ CI 0.75 to $1.01 ; \mathrm{P}=0.07$; fig 5). The test for interaction effect was not significant (ratio of relative risks $0.83,95 \%$ CI 0.63 to 1.09 ; $\mathrm{Z}=1.34, \mathrm{P}=0.18$ ).

Table 2 |Effect of moderate hypothermia on neurological outcomes at 18 months compared with controls

\begin{tabular}{|c|c|c|c|c|}
\hline & $\begin{array}{l}\text { Risk ratio } \\
(95 \% \mathrm{Cl})\end{array}$ & $\begin{array}{l}\text { Risk difference } \\
\qquad(95 \% \mathrm{Cl})\end{array}$ & $\begin{array}{l}\text { Number needed } \\
\text { to treat }(95 \% \mathrm{Cl})\end{array}$ & $P$ value \\
\hline Death or severe disability* & 0.81 (0.71 to 0.93$)$ & $-0.11(-0.18$ to -0.04$)$ & $9(5$ to 25$)$ & 0.002 \\
\hline Survival with normal outcome & $1.53(1.22$ to 1.93$)$ & $0.12(0.06$ to 0.18$)$ & $8(5$ to 17$)$ & $<0.001$ \\
\hline Mortality & 0.78 (0.66 to 0.93$)$ & $-0.07(-0.12$ to -0.02$)$ & $14(8$ to 47$)$ & 0.005 \\
\hline Severe disability in survivors* & 0.71 (0.56 to 0.91$)$ & $-0.11(-0.20$ to -0.03$)$ & $9(5$ to 30$)$ & 0.006 \\
\hline Cerebral palsy in survivors & 0.69 (0.54 to 0.89$)$ & $-0.12(-0.20$ to -0.04$)$ & $8(5$ to 24$)$ & 0.004 \\
\hline Severe neuromotor delay in survivorsł & $0.73(0.56$ to 0.95$)$ & $-0.10(-0.18$ to -0.02$)$ & $10(6$ to 71$)$ & 0.02 \\
\hline Severe neurodevelopmental delay in survivors§ & 0.71 (0.54 to 0.92$)$ & $-0.11(-0.19$ to -0.03$)$ & 9 (5 to 39$)$ & 0.01 \\
\hline Blindness in survivors & $0.57(0.33$ to 0.96$)$ & $-0.06(-0.11$ to 0.00$)$ & 17 (9 to 232$)$ & 0.03 \\
\hline Deafness in survivors & $0.76(0.36$ to 1.62$)$ & $-0.01(-0.05$ to 0.03 & NA & 0.47 \\
\hline
\end{tabular}

*Severe disability was defined in the CoolCap and TOBY trials as the presence of at least one of the following impairments: mental development index score of less than 70 ( 2 standard deviations below the standardised mean of 100) on the Bayley scales of infant development; gross motor function classification system level 3-5 (where the scale is from 1 to 5 , with 1 being the mildest impairment); or bilateral cortical visual impairment with no useful vision. The NICHD trial defined disability as a mental developmental index score of 70-84 plus one or more of the following impairments: gross motor function classification system level 2; hearing impairment with no amplification; or a persistent seizure disorder †Survival with normal outcome was defined as survival without cerebral palsy and with a mental developmental index score of more than 84 , a psychomotor developmental index score of more than 84 , and normal vision and hearing.

†Severe neuromotor delay was determined on the basis of a psychomotor developmental index score of less than 70 in survivors.

$\S$ Severe neurodevelopmental delay was determined on the basis of a mental developmental index score of less than 70 in survivors. 


\begin{tabular}{|c|c|c|c|c|c|c|c|}
\hline \multirow[b]{2}{*}{ Study or subgroup } & \multicolumn{2}{|c|}{ Hypothermia } & \multicolumn{2}{|c|}{ Normothermia } & \multirow[b]{2}{*}{$\begin{array}{l}\text { Risk ratio } \\
(95 \% \mathrm{Cl})\end{array}$} & \multirow[b]{2}{*}{$\begin{array}{l}\text { Weight } \\
\text { (\%) }\end{array}$} & \multirow[b]{2}{*}{$\begin{array}{c}\text { Risk ratio } \\
(95 \% \mathrm{Cl})\end{array}$} \\
\hline & Events & Total & Events & Total & & & \\
\hline \multicolumn{8}{|c|}{ Major neurodevelopmental disability in survivors } \\
\hline CoolCap & 23 & 72 & 31 & 68 & $=$ & 31.0 & $0.70(0.46$ to 1.07 \\
\hline $\mathrm{NICHD}$ & 21 & 78 & 26 & 65 & $=$ & 27.6 & $0.67(0.42$ to 1.08 \\
\hline TOBY & 32 & 120 & 42 & 117 & $=$ & 41.4 & $0.74(0.51$ to 1.09 \\
\hline Subtotal $(95 \% \mathrm{Cl})$ & & 270 & & 250 & - & 100.00 & $0.71(0.56$ to 0.91 \\
\hline Total events & 76 & & 99 & & & & \\
\hline \multicolumn{8}{|c|}{ Rate of cerebral palsy in survivors } \\
\hline TOBY & 33 & 120 & 48 & 117 & - & 49.0 & 0.67 (0.47 to 0.96 \\
\hline NICHD & 15 & 77 & 19 & 64 & $\rightarrow$ & 20.9 & $0.66(0.36$ to 1.18 \\
\hline CoolCap & 23 & 72 & 29 & 68 & $=$ & 30.1 & $0.75(0.48$ to 1.16 \\
\hline Subtotal $(95 \% \mathrm{Cl})$ & & 269 & & 249 & - & 100.00 & $0.69(0.54$ to 0.89 \\
\hline Total events & 71 & & 96 & & & & \\
\hline \multicolumn{8}{|c|}{ Rate of severe neuromotor delay (PD|<70) in survivors } \\
\hline TOBY & 27 & 114 & 37 & 109 & $=$ & 43.4 & 0.70 (0.46 to 1.06 \\
\hline CoolCap & 21 & 69 & 23 & 56 & $=$ & 29.1 & $0.74(0.46$ to 1.19 \\
\hline $\mathrm{NICHD}$ & 20 & 74 & 22 & 62 & $\rightarrow$ & 27.5 & $0.76(0.46$ to 1.26 \\
\hline Subtotal $(95 \% \mathrm{Cl})$ & & 257 & & 227 & $\bullet$ & 100.00 & 0.73 (0.56 to 0.95 \\
\hline Total events & 68 & & 82 & & & & \\
\hline \multicolumn{8}{|c|}{$\begin{array}{l}\text { Rate of severe neurodevelopmental delay (MDI<70) } \\
\text { in survivors }\end{array}$} \\
\hline TOBY & 28 & 115 & 38 & 110 & $=$ & 42.8 & 0.70 (0.47 to 1.06 \\
\hline CoolCap & 21 & 70 & 24 & 61 & $=$ & 28.3 & $0.76(0.47$ to 1.23 \\
\hline $\mathrm{NICHD}$ & 19 & 75 & 24 & 62 & + & 28.9 & 0.65 (0.40 to 1.08 \\
\hline Subtotal $(95 \% \mathrm{Cl})$ & & 260 & & 233 & - & 100.00 & 0.71 (0.54 to 0.92 \\
\hline Total events & 68 & & 86 & & & & \\
\hline \multicolumn{8}{|c|}{ Rate of blindness in survivors } \\
\hline CoolCap & 7 & 72 & 11 & 64 & $\rightarrow$ & 34.6 & 0.57 (0.23 to 1.37 \\
\hline $\mathrm{NICHD}$ & 5 & 75 & 9 & 63 & $\rightarrow$ & 29.0 & 0.47 (0.16 to 1.32 \\
\hline TOBY & 8 & 119 & 12 & 114 & $\rightarrow$ & 36.4 & $0.64(0.27$ to 1.50 \\
\hline Subtotal $(95 \% \mathrm{Cl})$ & & 266 & & 241 & $\bullet$ & 100.00 & 0.56 (0.33 to 0.96 \\
\hline Total events & 20 & & 32 & & & & \\
\hline \multicolumn{8}{|c|}{ Rate of deafness in survivors } \\
\hline CoolCap & 5 & 64 & 3 & 55 & - & 21.8 & $1.43(0.36$ to 5.72 \\
\hline $\mathrm{NICHD}$ & 3 & 77 & 4 & 64 & $\rightarrow$ & 29.5 & 0.62 (0.14 to 2.68 \\
\hline TOBY & 4 & 114 & 7 & 108 & $\rightarrow$ & 48.6 & 0.54 (0.16 to 1.80 \\
\hline Subtotal $(95 \% \mathrm{Cl})$ & & 255 & & 227 & 4 & 100.00 & 0.76 (0.36 to 1.61 \\
\hline \multirow[t]{2}{*}{ Total events } & 12 & & 14 & 0.001 & 0.1110 & 1000 & \\
\hline & & & & $\begin{array}{l}\text { Fave } \\
\text { hyp }\end{array}$ & mia no & $\begin{array}{l}\text { Favours } \\
\text { thermia }\end{array}$ & \\
\hline
\end{tabular}

Fig 3 | Forest plot of the effect of therapeutic hypothermia compared with standard care (normothermia) on neurological outcomes ("events"). All infants surviving to 18 months randomly assigned to either study arm were included in the analysis. A Mantel-Haenszel fixed effects model was used to calculate risk ratios and $95 \%$ confidence intervals. Studies shown are the Total Body Hypothermia (TOBY) trial, ${ }^{6}$ the National Institute of Child Health and Human Development (NICHD) trial, ${ }^{5}$ and the CoolCap trial. ${ }^{4}$ Abbreviations: MDI, mental developmental index score; PDI, psychomotor developmental index score

\section{DISCUSSION}

In the absence of any specific intervention to improve the dismal prognosis of infants with hypoxic-ischaemic encephalopathy, clinical enthusiasm for a novel treatment is understandable. However, individual trials do not provide unequivocal evidence of benefit from therapeutic hypothermia: two of the three studies that report neurological outcome at 18 months or more failed to detect a significant improvement in the primary outcome; differences exist in the apparent effect of hypothermia on important outcomes such as mortality; and uncertainty persists concerning the influence of clinical factors, such as disease severity, on treatment effect. These issues led to controversy and divergent views on the value of therapeutic hypothermia in infants with hypoxic-ischaemic encephalopathy. ${ }^{24-28}$ This new meta-analysis of the existing data on the topic, including the results of the TOBY trial, provides the highest level evidence that moderate hypothermia is efficacious in infants with hypoxic-ischaemic encephalopathy.

The completed trials included in this analysis were of high methodological quality, but none was able to blind treatment assignment; neurodevelopmental assessment, however, was masked in all the studies. The point estimates of treatment effect for primary and most secondary outcomes showed a striking consistency both between outcomes and across the trials. The risk ratio assigned to the primary outcome of death or disability in the three major trials was very similar, although in two trials the $95 \%$ confidence intervals crossed unity. Our metaanalysis, however, confirms that the overall effect of therapeutic hypothermia in infants with hypoxic-ischaemic encephalopathy is significant.

This uniformity is also seen in a number of secondary measures of neurodevelopmental outcome - in particular the rate of "normal" survival, where the point estimates for risk ratio were almost identical across the trials (although only significant in one study). Taken together, the homogeneity of the trial results gives a high level of confidence in the therapeutic benefit of prolonged moderate hypothermia.

Our findings are particularly remarkable given the differences between the studies in cooling method and trial protocol. All the three trials that reported neurological outcome at 18 months or more reduced whole body temperature as measured in the rectum or oesophagus, but the core temperature of $33-34^{\circ} \mathrm{C}$ in the TOBY and the NICHD trials was achieved by different cooling blankets and the temperature of $34-35^{\circ} \mathrm{C}$ in the CoolCap study by using head cooling. The TOBY trial, but not the NICHD or CoolCap trials, cooled infants during transport to the treatment centre, but the age at start of cooling was similar in the three studies. The minimal effect of these differences increases confidence that our findings can be generalised to the wider healthcare system and suggests that clinicians planning the widespread implementation of therapeutic hypothermia need be less concerned about the precise method of cooling and more focused on training of staff for its safe application.

\section{Influence of severity of encephalopathy}

An important question raised by clinicians caring for infants with hypoxic-ischaemic encephalopathy, and one to which individual trials offer discrepant answers, is whether it is possible to define a group of patients who are too severely affected to benefit from treatment with hypothermia, as was suggested by the CoolCap study ${ }^{4}$ To shed light on this issue we carried out a subgroup analysis to examine the interaction between disease severity and treatment effect. The primary outcome of death or disability at 18 months was 


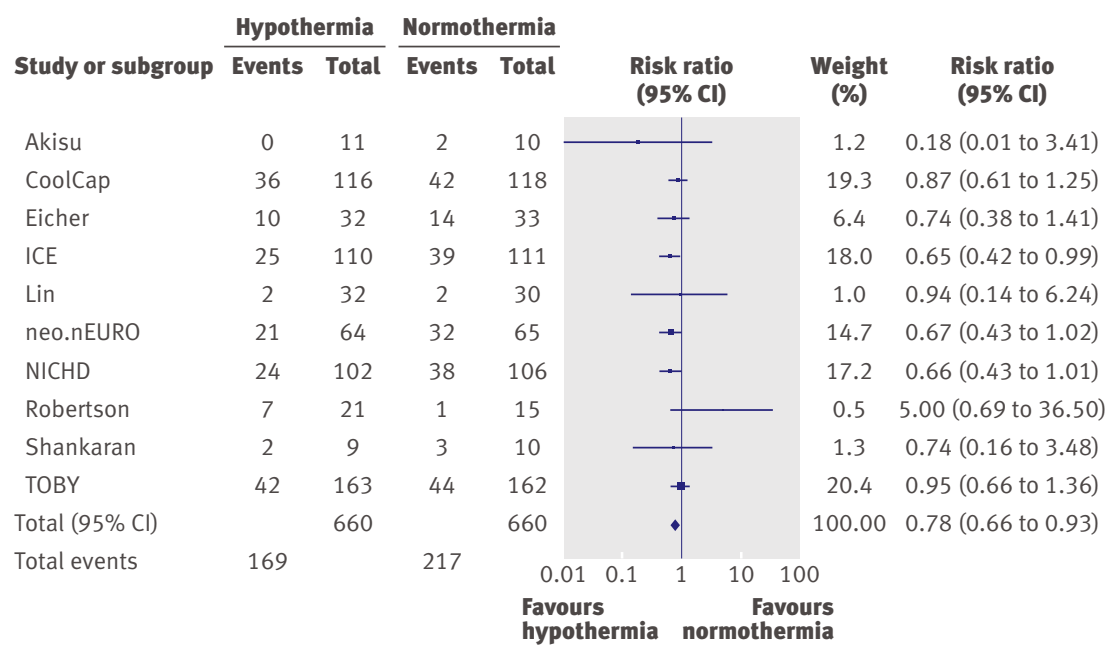

Fig 4 | Forest plot of the effect of therapeutic hypothermia compared with standard care (normothermia) on mortality ("events") in all 10 trials identified. Studies shown are Akisu et al (2003), ${ }^{17}$ the CoolCap trial, ${ }^{4}$ Eicher et al (2005), ${ }^{3}$ the Infant Cooling Evaluation (ICE) trial, ${ }^{13}$ Lin et al (2006) ${ }^{16}$ the neo.nEURO.network trial, ${ }^{14}$ the National Institute of Child Health and Human Development (NICHD) study, ${ }^{5}$ Robertson et al (2008), ${ }^{15}$ Shankaran et al (2002), ${ }^{18}$ and the Total Body Hypothermia (TOBY) trial. ${ }^{6}$ All infants randomly assigned to either study arm were included in the analysis. A Mantel-Haenszel fixed effects model was used to calculate risk ratios and $95 \%$ confidence intervals. Test for heterogeneity: $X^{2}=7.73$, degrees of freedom $=9$ $(P=0.56) ; I^{2}=0 \%$. Test for overall effect: $Z=2.89(P=0.005)$

significantly improved by hypothermia in moderately affected infants but not in severely affected babies. Until further data are available to clarify the effect of therapeutic hypothermia in infants with severe encephalopathy, the evidence may appropriately be interpreted to mean that although there is considerable confidence that infants with moderate encephalopathy will benefit overall from therapeutic hypothermia, it remains appropriate for clinicians to make individual

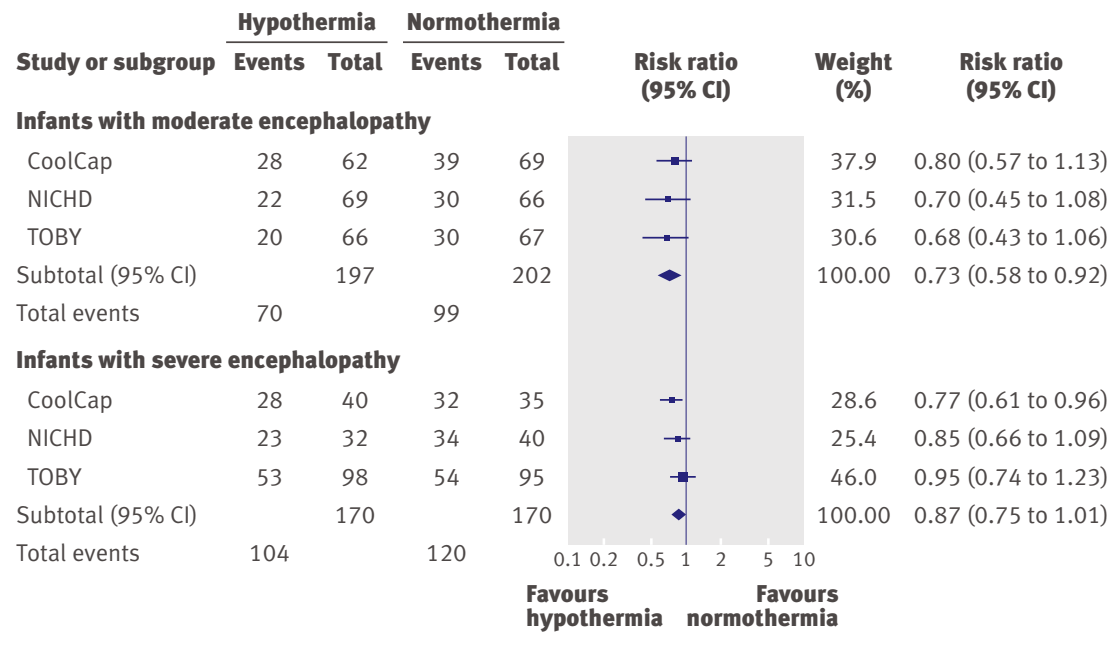

Fig 5 | Forest plot of the effect of therapeutic hypothermia compared with standard care (normothermia) on death or disability stratified by severity of encephalopathy ("events"). Assessment of grade of encephalopathy was by amplitude integrated electroencephalogram and clinical examination in the CoolCap ${ }^{4}$ and National Institute of Child Health and Human Development (NICHD) ${ }^{5}$ studies and by amplitude integrated electroencephalogram only in the Total Body Hypothermia (TOBY) study. ${ }^{6}$ All infants randomly assigned to either study arm were included in the analysis. A Mantel-Haenszel fixed effects model was used to calculate risk ratios and $95 \%$ confidence intervals decisions on whether to treat infants with severe encephalopathy.

\section{Limitations of study data}

Some caveats should be acknowledged when considering the evidence that hypothermia should be offered in the first 6 hours of life for infants with moderate to severe hypoxic-ischaemic encephalopathy. Firstly, no study has yet reported outcomes in later childhood after therapeutic hypothermia. Eighteen months is probably the earliest age at which a comprehensive assessment can be reliably carried out, although detection of cognitive and behavioural problems requires assessment later in childhood. ${ }^{29}$ Infants in the trials reported to date should be followed up to confirm that the neurological data recorded at 18 months accurately predict long term neurological function, particularly given that the current data make it unlikely that further randomised trials will be conducted in well resourced health economies.

Secondly, two further trials on therapeutic hypothermia for hypoxic-ischaemic encephalopathy are yet to report results, which might affect the conclusions of our study. However, the number of infants in the current meta-analysis (767 infants with neurological outcome reported at 18 months of age or more) is more than double that in the trials whose results are awaited (350 infants). Large trials that show a very large adverse effect of treatment would be required for the conclusions of the current meta-analysis to be materially changed; given the striking homogeneity of the current dataset, such findings can be regarded as unlikely. Indeed, preliminary presentation of these trials suggests that they also show a benefit from hypothermia. ${ }^{1516}$

Thirdly, the present data cannot necessarily be extrapolated to resource poor environments, given that care available, risk benefits, and costs of treatment are likely to differ from those in the settings of the studies that were analysed. The only study to report on hypothermic neural rescue in such an environment is a pilot study in Uganda that reported increased mortality in the treatment group. ${ }^{17}$ This finding appears to reflect chance allocation of more infants with severe encephalopathy to the treatment group. Furthermore, it is interesting to note that the great majority of infants in this small study were hypothermic at the time of randomisation, which may well affect the potential for further benefit. Although this point is not evidence that cooling is inappropriate in resource poor environments, it emphasises the importance of field trials in different environments and underlines the need to ensure that therapeutic hypothermia is only applied in the manner that has been tested in well conducted clinical trials (that is, with access to specialist newborn services and appropriate training and equipment).

\section{Conclusion}

The present analysis strongly supports the use of therapeutic hypothermia in newborn infants with hypoxicischaemic encephalopathy to reduce the risk of death 
What is already known on this topic

Prolonged moderate hypothermia is increasingly used to treat infants with hypoxicischaemic encephalopathy

It is uncertain whether therapeutic hypothermia improves important neurological outcomes, such as the rate of cerebral palsy, after perinatal asphyxia

What this study adds

Prolonged moderate hypothermia improves survival and reduces the rate of disability at 18 months of age in infants who survive hypoxic-ischaemic encephalopathy

The remarkable homogeneity of trial results provides unequivocal evidence of therapeutic benefit of prolonged moderate hypothermia

and neurological impairment at 18 months. Continued follow-up of the children enrolled in the studies included in our meta-analysis is essential to determine whether these benefits are maintained in later childhood.

Contributors: All the authors contributed to the study design, analysis of the data, and preparation of the manuscript. DA is the study guarantor. Funding: AJG was supported by the Health Research Council of New Zealand. Imperial College London (ADE and DA) and University of Oxford (PB, EJ, and BS) are Comprehensive Biomedical Research Centres. Competing interests: All authors have completed the Unified Competing Interest form at http://www.icmje.org/coi_disclosure.pdf (available on request from the corresponding author) and declare that (1) Olympic Medical Corp (Seattle, WA) loaned equipment to AJG, MT, and DA for pilot studies preceding the CoolCap trial. The University of Auckland has applied for a related patent that names AJG; however, AJG has no financial interest. DA, ADE, AJG, MT, and AW were members of the CoolCap trial scientific group. DA, PB, ADE, EJ, BS, HH, ML, MT, and AW were members of the TOBY trial scientific group and are members of the TOBY Children study scientific group. (2) The authors have no relationships with companies that might have an interest in the submitted work in the previous 3 years; (3) their spouses, partners, or children have no financial relationships that may be relevant to the submitted work; and (4) none of the authors have non-financial interests that may be relevant to the submitted work.

Ethical approval: Approval from an ethics committee was not required for this study.

1 Lawn J, Shibuya K, Stein C. No cry at birth: global estimates of intrapartum stillbirths and intrapartum-related neonatal deaths. Bull World Health Organ 2005;83:409-17.

2 Gunn AJ, Gunn TR. The 'pharmacology' of neuronal rescue with cerebral hypothermia. Early Hum Dev 1998;53:19-35.

3 Eicher DJ, Wagner CL, Katikaneni LP, Hulsey TC, Bass WT, Kaufman DA, et al. Moderate hypothermia in neonatal encephalopathy: efficacy outcomes. Pediatr Neurol 2005;32:11-7.

4 Gluckman PD, Wyatt JS, Azzopardi D, Ballard R, Edwards AD, Ferriero DM, et al. Selective head cooling with mild systemic hypothermia after neonatal encephalopathy: multicentre randomised trial. Lancet 2005;365:663-70.

5 Shankaran S, Laptook AR, Ehrenkranz RA, Tyson JE, McDonald SA Donovan EF, et al. Whole-body hypothermia for neonates with hypoxic-ischemic encephalopathy. N Engl J Med 2005;353:1574-84.

6 Azzopardi DV, Strohm B, Edwards AD, Dyet L, Halliday HL, Juszczak E, et al. Moderate hypothermia to treat perinatal asphyxial encephalopathy. N Engl J Med 2009;361:1349-58.

7 Jacobs S, Hunt R, Tarnow-Mordi W, Inder T, Davis P. Cooling for newborns with hypoxic ischaemic encephalopathy. Cochrane Database Syst Rev 2007;(4):CD003311.

8 Higgins RD, Raju TN, Perlman J, Azzopardi DV, Blackmon LR, Clark RH, et al. Hypothermia and perinatal asphyxia: executive summary of the
National Institute of Child Health and Human Development workshop. J Pediatr 2006;148:170-5.

9 Blackmon LR, Stark AR. Hypothermia: a neuroprotective therapy for neonatal hypoxic-ischemic encephalopathy. Pediatrics 2006;117:942-8.

10 Guidelines for reviewers and editors. Cochrane Neonatal Review Group, 2009. http://neonatal.cochrane.org.

11 Bayley N. Bayley scales of infant development. Harcourt Brace, 1993.

12 Altman DG, Bland JM. Interaction revisited: the difference between two estimates. BMJ 2003;326:219.

13 Jacobs SE, Stewart M, Inder T, Doyle LW, Morley CJ. ICE: the Australian cooling trial for hypoxic-ischemic encephalopathy-in hospital outcomes. Proceedings of the Hot Topics in Neonatology Conference, Washington, DC, Dec 7-9 2008.

14 Simbruner G, Mittal R, Rohlman F, Muche R. European nEURO. network trial. Proceedings of the Hot Topics in Neonatology Conference, Washington, DC, Dec 7-9 2008.

15 Robertson NJ, Nakakeeto M, Hagmann C, Cowan FM, Acolet D, Iwata $\mathrm{O}$, et al. Therapeutic hypothermia for birth asphyxia in lowresource settings: a pilot randomised controlled trial. Lancet 2008;372:801-3.

16 Lin ZL, Yu HM, Lin J, Chen SQ, Liang ZQ, Zhang ZY. Mild hypothermia via selective head cooling as neuroprotective therapy in term neonates with perinatal asphyxia: an experience from a single neonatal intensive care unit. J Perinatol 2006;26:180-4.

17 Akisu M, Huseyinov A, Yalaz M, Cetin H, Kultursay N. Selective head cooling with hypothermia suppresses the generation of plateletactivating factor in cerebrospinal fluid of newborn infants with perinatal asphyxia. Prostaglandins Leukot Essent Fatty Acids 2003;69:45-50.

18 Shankaran S, Laptook A, Wright LL, Ehrenkranz RA, Donovan EF, Fanaroff AA, et al. Whole-body hypothermia for neonatal encephalopathy: animal observations as a basis for a randomized, controlled pilot study in term infants. Pediatrics 2002;110:377-85.

19 Zhou WH, Shao XM, Zhang XD, Chen C, Huang GY. [Effects of hypothermia on cardiac function in neonates with asphyxia] Zhonghua Er Ke Za Zhi 2003;41:460-2.

20 Wyatt JS, Gluckman PD, Liu PY, Azzopardi D, Ballard R, Edwards AD, et al. Determinants of outcomes after head cooling for neonatal encephalopathy. Pediatrics 2007;119:912-21.

21 Shankaran S, Pappas A, Laptook AR, McDonald SA, Ehrenkranz RA, Tyson JE, et al. Outcomes of safety and effectiveness in a multicenter randomized, controlled trial of whole-body hypothermia for neonatal hypoxic-ischemic encephalopathy. Pediatrics 2008;122:e791-8.

22 Gunn AJ, Gluckman PD, Gunn TR. Selective head cooling in newborn infants after perinatal asphyxia: a safety study. Pediatrics 1998;102:885-92.

23 Battin MR, Dezoete JA, Gunn TR, Gluckman PD, Gunn AJ. Neurodevelopmental outcome of infants treated with head cooling and mild hypothermia after perinatal asphyxia. Pediatrics 2001;107:480-4.

24 Shah PS, Ohlsson A, Perlman M. Hypothermia to treat neonatal hypoxic ischemic encephalopathy: systematic review. Arch Pediatr Adolesc Med 2007;161:951-8.

25 Hoehn T, Hansmann G, Buhrer C, Simbruner G, Gunn AJ, Yager J, et al. Therapeutic hypothermia in neonates. Review of current clinical data, ILCOR recommendations and suggestions for implementation in neonatal intensive care units. Resus 2008;78:7-12.

26 Gunn AJ, Hoehn T, Hansmann G, Buhrer C, Simbruner G, Yager J, et al. Hypothermia: an evolving treatment for neonatal hypoxic ischemic encephalopathy. Pediatrics 2008;121:648-9.

27 Kirpalani H, Barks J, Thorlund K, Guyatt G. Cooling for neonatal hypoxic ischemic encephalopathy: do we have the answer? Pediatrics 2007;120:1126-30.

28 Barks J. Neonatal hypothermia: What are we waiting for? 2005. www. nicuniversity.org/downloads/Neonatal Hypothermia.pdf.

29 Barnett AL, Guzzetta A, Mercuri E, Henderson SE, Haataja L, Cowan F, et al. Can the Griffiths scales predict neuromotor and perceptualmotor impairment in term infants with neonatal encephalopathy? Arch Dis Child 2004;89:637-43.

Accepted: 9 December 2009 